UCRL-JC-123187

PREPRINT

\title{
Growth of Silicon Carbide on Silicon via Reaction of Sublimed Fullerenes and Silicon
}

\author{
A.V. Hamza \\ M. Balooch
}

RECEVED

APR 059,5

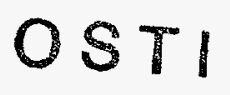

This paper was prepared for submittal to the 189 th Meeting of the Electrochemical Society

Anaheim, CA

May 20-24, 1996

February 1996

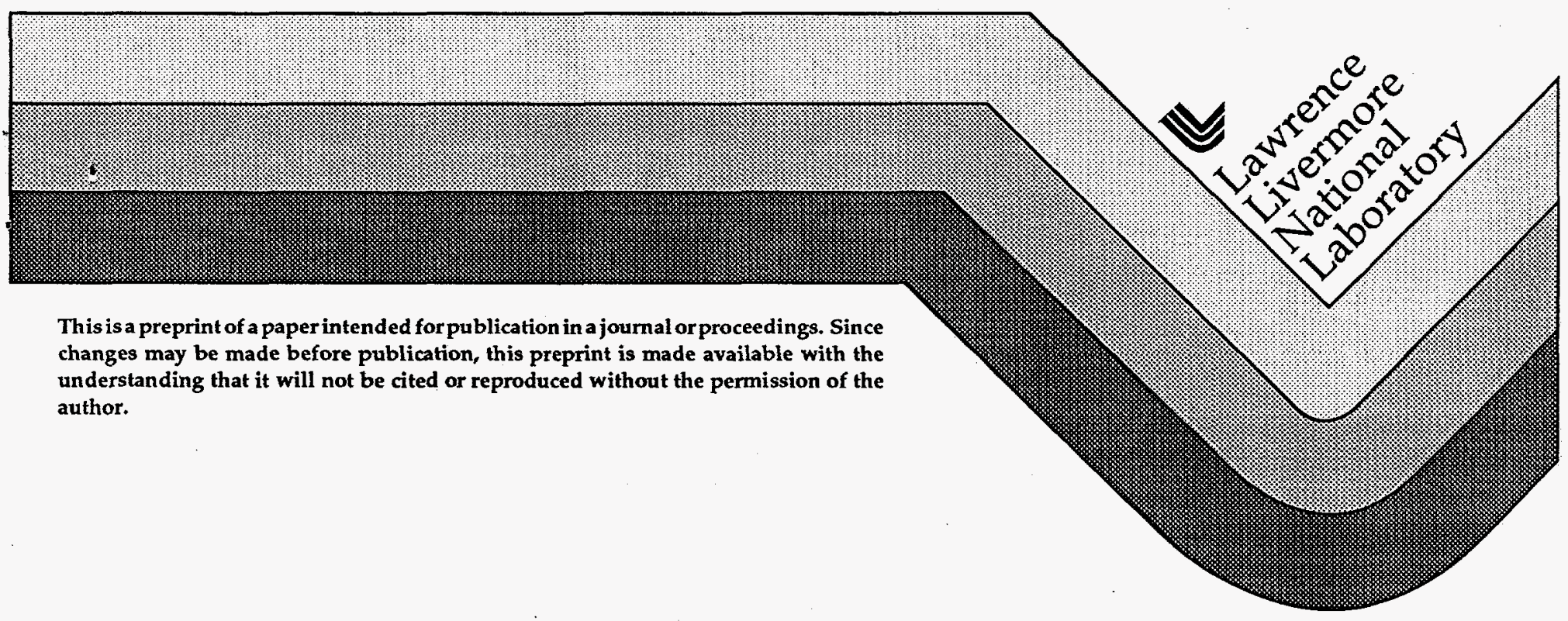




\section{DISCLAIMER}

This document was prepared as an account of work sponsored by an agency of the United States Government. Neither the United States Government nor the University of California nor any of their employees, makes any warranty, express or implied, or assumes any legal liability or responsibility for the accuracy, completeness, or usefulness of any information, apparatus, product, or process disclosed, or represents that its use would not infringe privately owned rights. Reference herein to any specific commercial product, process, or service by trade name, trademark, manufacturer, or otherwise, does not necessarily constitute or imply its endorsement, recommendation, or favoring by the United States Government or the University of California. The views and opinions of authors expressed herein do not necessarily state or reflect those of the United States Government or the University of California, and shall not be used for advertising or product endorsement purposes. 


\section{DISCLAMMER}

Portions of this document may be illegible in electronic image products. Images are produced from the best available original document. 


\title{
GROWTH OF SILICON CARBIDE ON SILICON VIA REACTION OF SUBLIMED
} FULLERENES AND SILICON

\author{
A. V. Hamza and M. Balooch \\ Chemistry and Materials Science Directorate \\ University of California, Lawrence Livermore National Laboratory \\ Livermore, CA 94550
}

Keywords: Fullerenes, Silicon Carbide, Void Formation, Low Energy Electron Diffraction (LEED) 


\title{
GROWTH OF SILICON CARBIDE ON SILICON VIA REACTION OF SUBLIMED FULLERENES AND SILICON
}

\author{
A. V. Hamza and M. Balooch \\ Chemistry and Materials Science Directorate \\ University of Califormia, Lawrence Livermore National Laboratory \\ Livermore, CA 94550
}

\begin{abstract}
Epitaxial silicon carbide films are grown on $\mathrm{Si}(100)$ substrates at a surface temperature of $1200 \mathrm{~K}$ via fullerene precursors. Films have been grown up to a thickness of $2500 \AA$. The growth rate of the SiC film is not limited by the surface reaction rate of fullerene with silicon at these temperatures, rather by the arrival rate of the reactants $\mathrm{Si}$ (by diffusion from substrate or from gas phase) or fullerene. This results in rapid film growth. Films have been characterized by low energy electron diffraction, ultraviolet photoelectron spectroscopy and Auger electron spectroscopy. Stoichiometric, epitaxial SiC films are grown. Supply of silicon to the growing $\mathrm{SiC}$ surface via sublimation greatly reduces the tendency for silicon diffusion to form voids at the $\mathrm{Si} / \mathrm{SiC}$ interface.
\end{abstract}

\section{INTRODUCTION}

The growth of $\mathrm{SiC}$. films on silicon substrates by conventional chemical vapor deposition techniques is expensive because of the high temperatures required in deposition reactors $(-1700 \mathrm{~K}$ or higher). In addition $\mathrm{SiC}$ is extremely inert, and thus, forming device structures on blanket deposited films is also time consuming. By taking advantage of the reactive properties of fullerenes on silicon substrates and silicon oxide substrates epitaxial $\mathrm{SiC}$ films can be selectively grown at relatively low substrate and gas temperatures of 900 to $1250 \mathrm{~K}(1)$.

Moalem et al. (2) have demonstrated that while $\mathrm{C}_{60}$ accommodates thermally with an silicon dioxide surface, $\mathrm{C}_{60}$ is unreactive at surface temperatures below $1250 \mathrm{~K}$ with silicon dioxide. In addition, the surface mobility of $\mathrm{C}_{60}$ on silicon dioxide is quite high, i.e. $\mathrm{C}_{60}$ behaves like a two-dimensional gas. Many groups (3-5) have shown that fullerenes react at temperatures above $900 \mathrm{~K}$ with silicon substrates to form SiC. Making use of the different interactions of fullerenes with silicon and silicon dioxide leads to a straightforward process to selectively grow $\mathrm{SiC}$ on silicon substrates. A silicon wafer patterned with silicon dioxide by semiconductor industry standard lithographic techniques is exposed to a fullerene vapor stream at substrate temperatures between 950 and $1250 \mathrm{~K}$. $\mathrm{SiC}$ grows on the bare silicon areas. After reaction the silicon dioxide is stripped from the wafer by rinsing in hydrofluoric acid, leaving a wafer patterned with $\mathrm{SiC}$.

Unfortunately, the silicon necessary to grow the $\mathrm{SiC}$ film is supplied from the wafer substrate by diffusion $(1,6)$. For small structures on the order of $1-5$ micron feature size, interface and surface diffusion is fast enough to supply silicon to the SiC growth area. This leads to undercut of the feature for thick ( 1 micron) SiC films (6). For larger 
features diffusion of $\mathrm{Si}$ through the growing $\mathrm{SiC}$ film is the mechanism by which the surface is supplied with silicon. This leads to void formation at the $\mathrm{Si} / \mathrm{SiC}$ interface, which are nucleated at defects (6).

In this paper we show that void formation can be strongly reduced by supplying silicon to the growing $\mathrm{SiC}$ film from the gas phase. The silicon carbide films were grown on a silicon substrate by first depositing sufficient $\mathrm{Si}$ to cover the substrate, and subsequently, depositing a monolayer of fullerene at room temperature. Heating the substrate to $1200 \mathrm{~K}$ converts the silicon-fullerene sandwich to $\mathrm{SiC}$.

\section{EXPERIMENTAL}

Experiments were performed in an ultra-high vacuum (UHV) apparatus. The low energy electron diffraction (LEED) apparatus is equipped with reverse view LEED optics and a cylindrical mirror analyzer for Auger electron spectroscopy (AES). Silicon (100) substrates were resistively heated and the temperature monitored either by a $\mathrm{K}$ type thermocouple or by optical pyrometer. A fullerene doser supplied fullerene vapor to the sample substrate by sublimation. A silicon doser supplied silicon by sublimation as well.

\section{RESULTS AND DISCUSSION}

$\mathrm{SiC}$ films have been grown on a $\mathrm{Si}(100)$ substrate by first nucleating $\mathrm{SiC}$ by depositing a multilayer of $\mathrm{C}_{60}$ on the wafer at room temperature and then heating the wafer to $1200 \mathrm{~K}$. On the nucleated $\mathrm{SiC}$ layer at room temperature enough $\mathrm{Si}$ is sublimed such that the carbon $272 \mathrm{eV}$ AES peak is at the detection limit. Then a multilayer of $\mathrm{C}_{60}$ is deposited on the silicon layer also at room temperature. The sample is then heated to $1200 \mathrm{~K}$. This is considered a single deposition cycle. Between cycles the surface composition and structure are monitored by AES and LEED. Stoichiometric SiC is grown epitaxially by this technique. Even $(2 \times 1)$ and $(3 \times 1)-(100) \mathrm{SiC}$ surface reconstructions were observed in the LEED patterns. After 60 cycles, $-2500 \AA$ of $\mathrm{SiC}$ had been grown as determined by cross section scanning electron microscopy. Voids at the $\mathrm{Si} / \mathrm{SiC}$ interface were observed at $-250 / \mathrm{cm}^{2}$. This is approximately a five order of magnitude reduction in the void formation as compared to the case were no silicon is supplied from the gas phase.

Unfortunately, different growth parameters are required. A smooth surface is not grown everywhere by this technique. Roughly spherical mounds of $\mathrm{SiC}$ embedded in the $\mathrm{SiC}$ film are observed at a highest density of $107 / \mathrm{cm}^{2}$ and with sizes from 0.6 to 0.3 microns in diameter by atomic force microscopy. The mounds are confirmed to be $\mathrm{SiC}$ by scanning Auger microscopy. The size of the mounds and the density correlated with the sublimed silicon. In areas were the sublimed silicon flux was smallest the density and size of mounds was also smallest $\left(\sim 106 / \mathrm{cm}^{2}\right.$ and 0.2 micron diameter).

Sublimed silicon deposited on graphite surfaces clusters upon heating of the substrate (7). If clustering were to occur on SiC during the heating of the wafer, this could be the mechanism of mound formation. The clustered silicon atoms may nucleate a new SiC 
domain. Simultaneous deposition of fullerene and silicon at appropriate $\mathrm{SiC}$ growth temperatures may eliminate the mound formation.

Ultraviolet photoelectron spectroscopy was used to probe the electronic properties of the $\mathrm{SiC}$ films grown via fullerene precursors. The work function of the sample is measured to be $4.8 \pm 0.1 \mathrm{eV}$, which is similar to that for bulk SiC. The work function increases slightly $(0.13 \mathrm{eV})$ with exposure (2 Langmuir) to dioxygen at room temperature as measured by a Kelvin probe (resolution $\pm 0.01 \mathrm{eV}$ ). The increase is likely due to physisorption of dioxygen on the surface, since the effect $(0.05 \mathrm{eV}$ increase at 2 Langmuir at $443 \mathrm{~K})$ decreases with surface temperature. At high temperature $(810 \mathrm{~K})$ exposure to dioxygen has no effect on the work function, which is in surprising contrast to silicon surfaces where the work function decreases by $0.3 \mathrm{eV}$ with exposure to dioxygen. The decrease for silicon is attributed to oxidation of the surface. The resistance of the SiC surface to oxidation is evidenced by the lack of change in the work function during exposure of the surface to dioxygen at $810 \mathrm{~K}$

\section{SUMMARY}

Stoichiometric, epitaxial $\mathrm{SiC}$ films can be grown via reaction of fullerenes with sublimed silicon on silicon substrates. Sublimed silicon greatly reduces the void formation at the $\mathrm{Si} / \mathrm{SiC}$ interface by 5 orders of magnitude. The electronic properties of the silicon carbide surface film indicate that the surface is not easily oxidized in the presence of dioxygen at high temperature, $810 \mathrm{~K}$.

\section{ACKNOWLEDGMENTS}

The authors thank J. Yoshiyama for scanning electron microscopy and Dr. M. A. Schildbach for scanning Auger microscopy. The work was performed under the auspices of the USDOE at Lawrence Livermore National Laboratory, contract \# W-7405-ENG-48.

\section{REFERENCES}

(1) A. V. Hamza, M. Balooch, and M. Moalem, Surface Science 317, L1129 (1994).

(2) M. Moalem, M. Balooch, A. V. Hamza, W. J. Siekhaus, and D. R. Olander, Journal of Chemical Physics 99, 4855 (1993); A. V. Hamza, M. Balooch, M. Moalem, and D. R. Olander, Chemical Physics Letters 228, 117 (1994).

(3) T. Hashizume, X.-D. Wang, Y. Nishina, H. Shinohara, Y. Saito, Y. Kuk, and T. Sakurai, Japanese Journal of Applied Physics 31, L880 (1992); T. Sakurai, X.-D. Wang, T. Hashizume, Y. Nishina, H. Shinohara, and Y. Saito, Applied Surface Science 67, 281 (1993); X.-D. Wang, T. Hashizume, H. Shinohara, Y. Saito, Y. Nishina, and T. Sakurai, Physical Review B 47, 15923 (1993).

(4) A. V. Hamza and M. Balooch, Chemical Physics Letters 201, 404 (1993); M. Balooch and A. V. Hamza, Applied Physics Letters 63, 150 (1993).

(5) D. Chen and D. Sarid, Physical Review B 49, 7612 (1994). 
(6) M. Balooch and A. V. Hamza, Recent Advances in the Chemistry and Physics of Fullerenes and Related Materials: Volume 2, Editors R. S. Ruoff and K. Kadish, The Electrochemical Society Proceedings Series, Pennington, NJ (1995).

(7) L. N. Dinh, L. L. Chase, M. Balooch, L. J. Terminello, and F. Wooten, Appl. Phys. Lett. 65, 3111 (1994). 